\title{
Integration and management of solar energy for electric vehicle charging station
}

\author{
Asif Khan ${ }^{1}$, Saim Memon ${ }^{1}$, Tariq Sattar ${ }^{1}$ \\ ${ }^{1}$ London South Bank University, London (United Kingdom)
}

\begin{abstract}
A rise of electric vehicles and consequent increase of charging stations in the UK has widely been acknowledged due to its negligible carbon emissions leading to the transformation of low-carbon economy. A dynamic increase in the wind and solar power systems installation and grid-integration to the charging stations of electric vehicles has led uncertainty issues in the power distribution grid e.g voltage fluctuations, transients/harmonics. This paper addresses the uncertainty scenario aiming to contribute and propose a potential model focusing on the design of the route in which solar electric power is delivered to the electric vehicle charging station. A specialised system containing an electrical control system is proposed using MATLAB and SIMULINK. A system was designed for improving the interaction among electric-vehicle charging points and battery storage system in which electrical control system assists in developing the correct duty cycle in order to stabilise and regulate the voltage at the DC/DC power conversion station. The proposed system is very effective and significant contribution in understanding and reducing the load on the converter untimely enabling reduction of charging time for electric vehicles. The implemented electrical control system manages the electric power on the grid such as during the peak times it draws power from the batteries and then charges up the batteries in the off-peak times. A constant voltage is achieved on the micro grid irrespective of fluctuations in solar energy generation and in the load.
\end{abstract}

Keywords: Solar system, Power conversion, Electric vehicles, storage system, charging station

\section{Introduction}

Around 550000 hybrid electric vehicles are reported to be registered in 2015 by the centre of solar energy and hydrogen research (Shaaban et al, 2015). The storage energy based electric-vehicles are classified into plug-in hybrid electric vehicles (Han et al, 2017).The main factor in the revolution of electric-vehicles is due to the improvement in power electronics components, better performance of electric machines and the storage system (Shen et al, 2014). The power electronics components such as switches, converters and drives increase the performance of power conversion. Beside this, development of software for hybrid electric vehicles is a silent revolution. The hybrid electric vehicles combine the motor of propulsion and ICE (Guan and Chen, 2017). An increase of plug-in electric vehicles are due to the several reasons such as it generates no carbon emissions due to the usage of no fossil fuels and long-term sustainable mission of transforming cities towards 100\% renewable and make cities better economically (Yu, 2017 and Zhang, 2016 ) because the carbon dioxide emissions was $407.70 \mathrm{ppm}$ in May 2016 and is continuously increasing (Cheng et al, 2015). Currently, the state of art uses to charge up the batteries in the hybrid electric vehicles are fuel cells, regenerative breaking system, and the vehicles charging station. These vehicle charging stations are connected to the National transmission energy network (Dubarry et al, 2017). Charging up the electric vehicles from the distribution network is not suitable as it increases the electrical demand on the network and creates power flow issues on the distribution network such as transients, harmonics and voltage reductions (Sheng et al, 2017). The power supply to the electric-vehicles can be AC or DC type. AC type power flow is not suitable for the electric-vehicle (EV) charging station as it increases charging time. The DC type power flow reduces the charging time and increases the performance of the electric-vehicles (Tan, 2016) and (Yong, 2015). DC power flow system also reduces the power losses due to shorter in length for the EV charging station. The purpose of designing such system is to reduce the power flow issues such as voltage fluctuations and transients/harmonics and issues at the existing transmission system. The DC grid is fed from 
the solar energy where power generation is always fluctuating, therefore, a control system required that transmits the signal at a very faster rate (Liu and Sun, 2014).

This paper presents the Simulink model for the solar storage system that transmits high DC voltage to the charging station. This is due to the unpredictable power generation from the solar system, it is a challenge to supply the constant required voltage to the electric vehicle. Beside this, quality ratings and stability are the main factors to charge up the large numbers of electric vehicle instantly. Due to these issues imbalances occur and harmonics and voltage sags arise. The research investigates the voltage efficiency and power flow management of solar energy transmission to the electric-vehicle charging station. This system has the ability to manage the power flow between generation and the loads. Under normal conditions, it is connected to the solar energy system and the storage battery bank and can be linked with fuel generator if required.

\section{Methodology}

A solar energy system capacity of $200 \mathrm{kWh}$ is simulated on MATLAB/SIMULINK in which the $200 \mathrm{kWh}$ storage system is added to balance the energy demands during the higher temperatures and low irradiance.This storage system is charged up from the solar system and the fuel generator is also added of capacity $200 \mathrm{kWh}$ that charging up the storage system after the energy falls to $60 \%$. The storage system supplies power to the electric-vehicle charging station during the disturbances and reduction in nominal power generation from the solar system. The electric-vehicle charging station has maximum power consumption capacity of $103.50 \mathrm{kWh}$ consisted of four charging points. DC/DC power conversion is carried out by using insulated gate bipolar transistors (IGBT) where MATLAB function coding environment is used to control the frequency of the IGBT and to stabalize the voltage from the solar system. By using low pass filter, spikes and transients are mitigated to achieve power quality. It is investigated how the temperature, irradiance, and over loading affects the power regulation on the system. Specifically, voltage instability and the transients are investigated. Programmable protection circuit breakers are placed to protect the charging terminal. Controlled power conversion system and analytical techniques are implemented to control the power flow in the system.

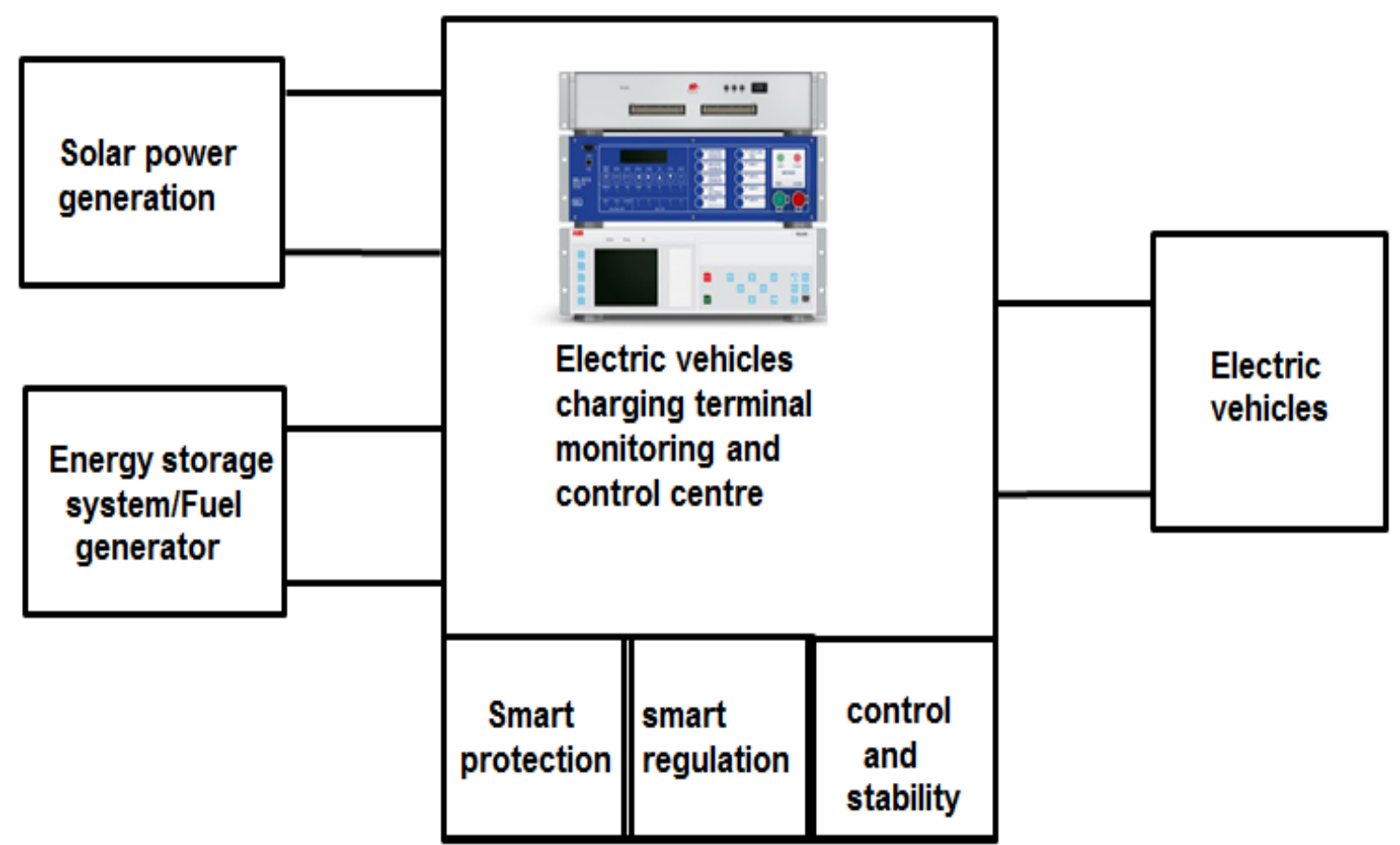

Fig. 1: illustrates the schematic model of the proposed system in which solar energy/storage system are maintaining the energy demands at the electric-vehicle charging station, smart monitoring and control system are used to convert and regulate the power flow from the storage and the solar system consisting of controlled DC/DC converter that is connected with the energy resources and the electric-vehicle loads 


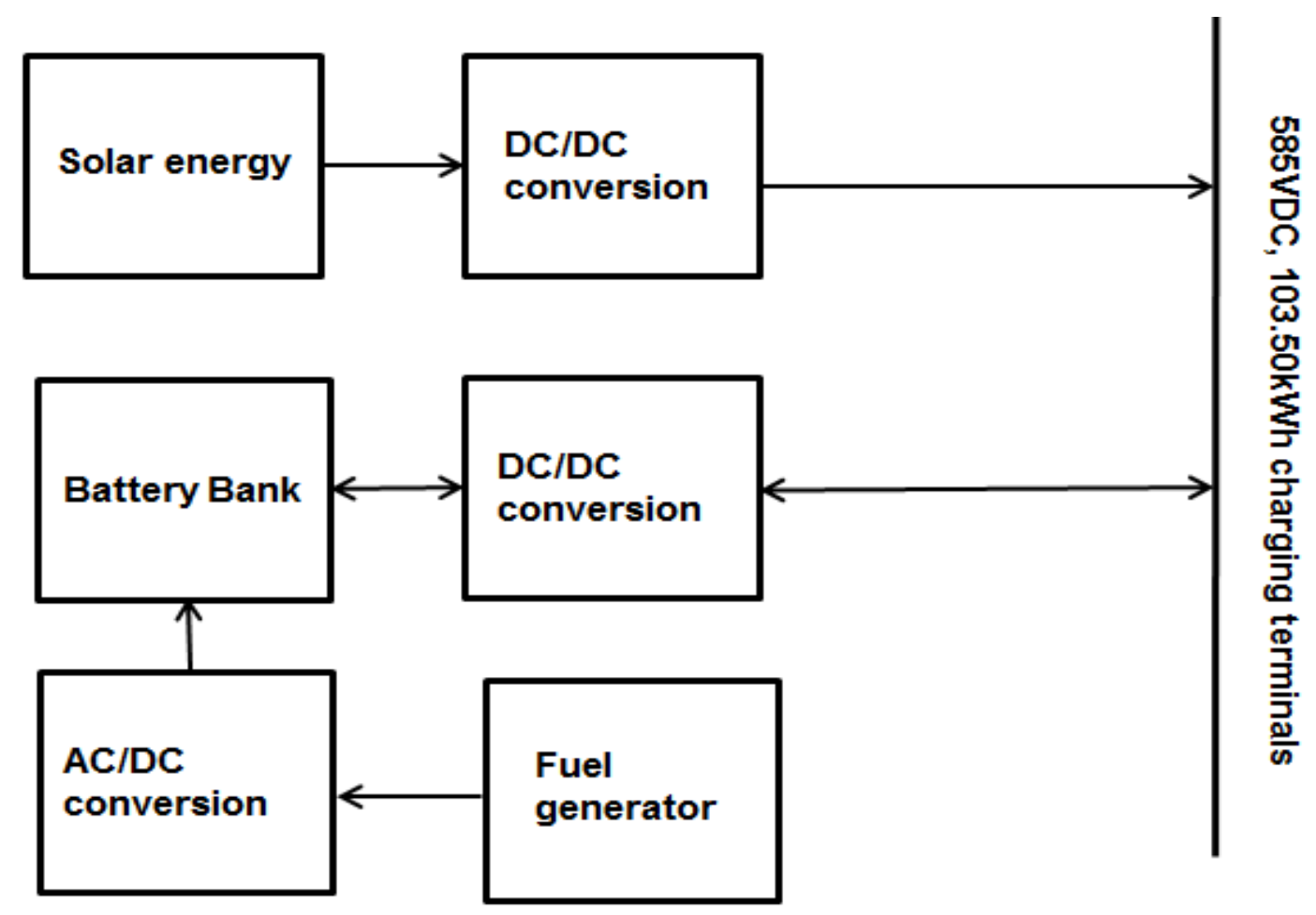

Fig. 2: is the block diagram of the power conversion for the solar system, fuel generator and the storage system in which the power flow between the storage system and the charging station is considered to be dual flow, meaning storage system can supply and receive energy from the charging station.

\section{Discussion}

The proposed structure consists of solar energy system, monitoring and control structure, measurements units, energy storage system, fuel based electric power generation system and power conversion system. The EV charging terminal consists of programmable protection system and a voltage regulator that assists to supply the quality power. The electric-vehicle charging station is receiving the electric power from the solar and storage system. The nominal power generated by the solar system is $200 \mathrm{kWh}$. The voltage from the solar system is converted to 585VDC that reduces the charging time for the electric vehicles. Irradiance and temperature block is used to provide sun power to the panels. Input from the irradiance is varying. Voltage source converters are used to convert the power from the solar farm. Then this power was added to the DC/DC converter station where a buck-boost converter is placed to balance the voltage. Low pass filter is applied to remove the transients and harmonics. It also supports to control the current and maintain the DC voltage level. A bi-directional converter is placed between the DC microgrid and the battery bank that charges up and discharges the batteries from the microgrid and it monitors the power flow at the grid and battery bank. During the peak time, battery storage system is dependent on the solar power generation unit, the fuel generator takeover to meet the energy demand. This topology is considered to improve the power flow on the transmission network due to the reduction in harmonics and voltage fluctuations. Transients and spikes arise in the system are also due to the installations of super capacitors at the electric-vehicles storage system. This reduces the efficiency of the power flow on the system because inductively behaves superlative at lower frequencies and capacitance load show good performance at higher frequencies. Due to DC power system, there is no phase shift between current and voltage but the voltage stability needs attention which can be maintained by supplying the correct pulses to the power converter switches.

List of energy converters connected to the electric-vehicle terminal.

- DC/DC energy conversion system for the solar energy system.

- $\mathrm{AC} / \mathrm{DC}$ energy conversion system from the fuel generator.

- DC/DC power conversion system for the storage system.

- Monitoring and control centre energy measurement and regulation system 
The DC/DC buck converters are used to transmit the regulated voltage to the electric-vehicles. To create the mathematical formulation constant voltage and constant power is assumed to be flowing out from the energy converter terminals. The constant voltage is achieved by applying the $50 \mathrm{kHz}$ frequencies at the converter switches. The resistance of the tranmsitted conductor is considered constant. The capacitance and inductance are neglected due to DC type power flow system.

The power flow into the terminals is splitted into three subsets $\{\mathrm{V}, \mathrm{R}, \mathrm{P}\}$ and the constant controlled voltage is received from the solar system/storage system. Branches of the terminal for voltage source converters are represented by $\mathrm{V}=\mathrm{N} \times \mathrm{N}$ included the constant resistance of the conductor. The electric vehicle charging terminal converts the 585VDC into the voltage required to charge the electric-vehicle batteries and the supercapacitors. The terminal voltage and current admittance matrix on the system $G \in \mathrm{R}^{\mathrm{N} \times \mathrm{N}}$ is expressed as follows,

$\left[\begin{array}{l}\mathrm{I}_{V} \\ \mathrm{I}_{\mathrm{R}} \\ \mathrm{I}_{\mathrm{P}}\end{array}\right]=\left[\begin{array}{lll}\mathrm{G}_{\mathrm{VV}} & \mathrm{G}_{\mathrm{VR}} & \mathrm{G}_{\mathrm{VP}} \\ \mathrm{G}_{\mathrm{RV}} & \mathrm{G}_{\mathrm{RR}} & \mathrm{G}_{\mathrm{RP}} \\ \mathrm{G}_{\mathrm{PV}} & \mathrm{G}_{\mathrm{PR}} & \mathrm{G}_{\mathrm{PP}}\end{array}\right] \cdot\left[\begin{array}{c}\mathrm{V}_{\mathrm{V}} \\ \mathrm{V}_{\mathrm{P}} \\ \mathrm{V}_{\mathrm{R}}\end{array}\right]$

Where $\mathbf{I}_{\mathbf{R}}=-\mathbf{D}_{\mathbf{R R}} \cdot \mathbf{V}_{\mathbf{R}}$

For the electric-vehicle charging terminal singular matrix can be written as shown in equation 3 . Where $\mathrm{B}$ is the susceptance and $D_{R R}$ is a diagonal matrix is for admittance.

$V_{R}=-\left(D_{R R}+G_{R R}\right)^{-1}\left(G_{R V} \cdot V_{V}+G_{R P} \cdot V_{P}\right)$

$\mathrm{I}_{\mathrm{P}}=\mathrm{J}_{\mathrm{P}}+\mathrm{B}_{\mathrm{PP}} \cdot \mathrm{V}_{\mathrm{P}}$

The voltage received from the storage/solar system is 585VDC. Power links are evaluated by the following equations where $I_{P}$ is the current level and $V_{P}$ is the voltage flow on the system.

$\mathrm{P}_{\mathrm{P}}=\operatorname{diag}\left(\mathrm{V}_{\mathrm{P}}\right) \cdot \mathrm{I}_{\mathrm{P}}$

The storage system is balancing the power flow on the system during the peak times and reduction in power generation from the designed solar system. The electric-vehicle charging terminal detects the power deficiency and switches $\mathrm{ON}$ the storage system. $\mathrm{P}_{\mathrm{P}}$ is evaluated to

$P_{P}=\operatorname{diag}\left(V_{P}\right) \cdot\left(J_{P}+B_{P P} \cdot V_{P}\right)$

With $\left.\mathbf{J}_{\mathbf{p}}=\mathbf{G}_{\mathbf{P V}}-\mathbf{G}_{\mathbf{P R}} \cdot\left(\mathbf{D}_{\mathbf{R R}}+\mathbf{G}_{\mathbf{R R}}\right)^{-\mathbf{1}} \cdot \mathbf{G}_{\mathbf{R V}}\right) \cdot \mathbf{V}_{\mathbf{V}}$

$B_{P P}=G_{P P}-G_{P R} \cdot\left(D_{R R}+G_{R R}\right)^{-1} \cdot G_{R P}$

The voltage in the terminals can be set by the solving the equation 9 .

$V_{P}=B_{P P}^{-1} \cdot\left(\operatorname{diag}\left(V_{P}^{-1}\right) \cdot P_{P}-J_{P}\right)$

To investigate the $V_{P}$, let consider $T \rightarrow R_{P}$

$\mathrm{TV}_{\mathrm{P}}=\mathrm{B}_{\mathrm{PP}}^{-1} \cdot\left(\operatorname{diag}\left(\mathrm{V}_{\mathrm{P}}^{-1}\right) \cdot \mathrm{P}_{\mathrm{P}}-\mathrm{J}_{\mathrm{P}}\right)$

The voltage is stabilised at the monitoring and control centre in order to maintain the energy flow for the electric-vehicles at the station. The reduction in voltage is maintained by correcting the applied frequency to the converter switches. Fuel generator is connected with the battery to maintain the power storage on the storage system during the energy shortages. 


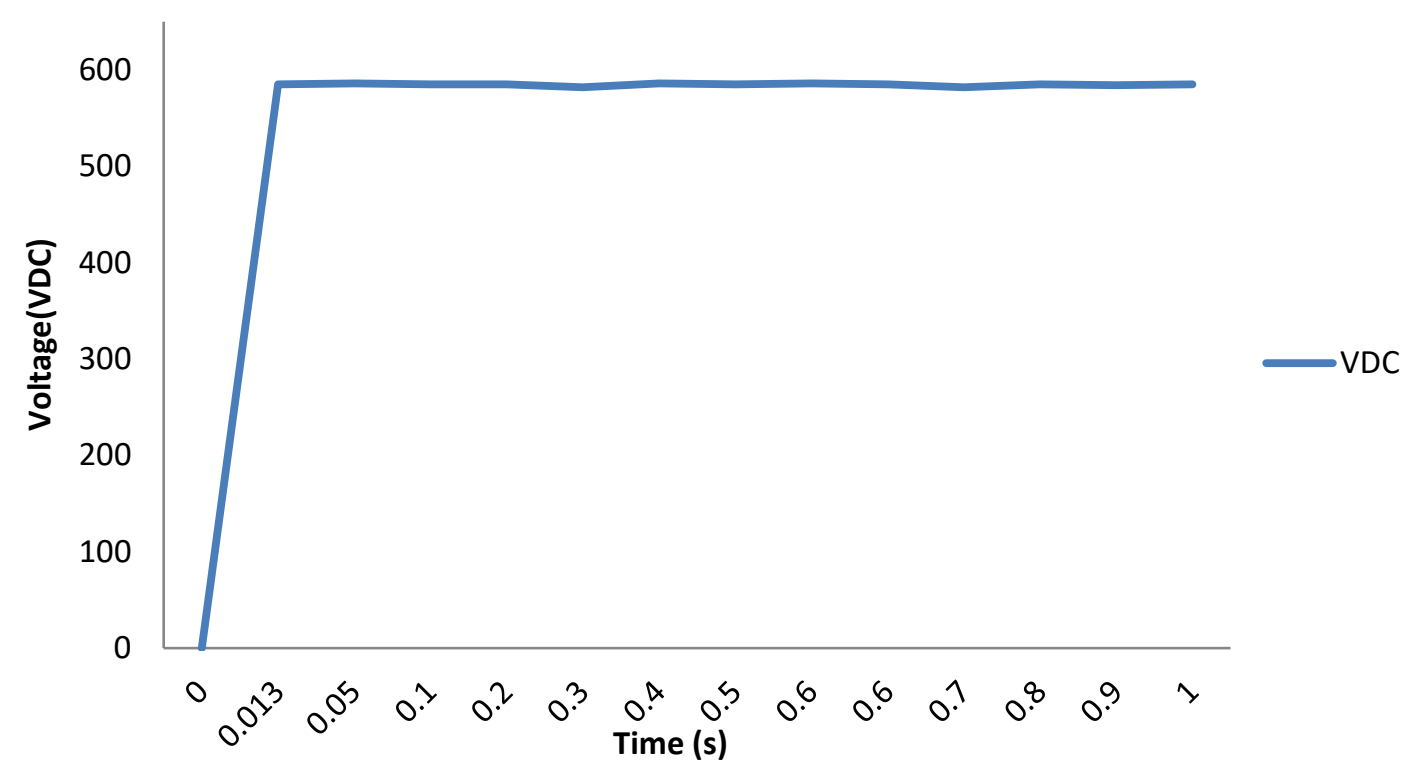

Fig. 3: The voltage output from the DC/DC converter of solar energy system

Tab. 1: The energy generation and storage capacity.

\begin{tabular}{|c|c|}
\hline Energy resources & Capacity \\
\hline Solar system & $200 \mathrm{kWh}$ \\
\hline Storage system & $200 \mathrm{kWh}$ \\
\hline Fuel Generator & $200 \mathrm{kVA}$ \\
\hline
\end{tabular}

\subsection{System performance}

With the rapid increase in power consumption at the EV charging terminal, following are the three issues linked with the storage/solar system.

- Quick energy supply from the storage system into the EV charging terminal

- Quick energy injection from the solar system to the charging station.

- Dynamic behaviour instead of long term serving capacity of the storage system.

There are four EV charging points taken for this system. These charging points are associated with the faster charging because of connection with the higher DC voltage of 585 VDC. The charging point consumes 50 $\mathrm{kWh}, 43 \mathrm{kWh}, 7 \mathrm{kWh}, 3.5 \mathrm{kWh}$. The proportion is selected based on the charging points being installed several places in the UK such as $2 \times 50 \mathrm{kWh}$ and $1 \times 43 \mathrm{kWh}$ in Toddington Dunstable at M1 motorway and similar are installed at the china town at London, charter street at Leicester and many other places in the UK. The batteries in the electric vehicles support to run the machines, but the batteries take longer to charge up. During the running period engine are used to charge up the batteries in the electric vehicles. To solve the faster charging for the EV batteries a new system is investigated. Higher voltage DC power supply is found more appropriate to solve this issue. The investigated system has the features to supply the energy during peak/off-peak times at the EV charging station by means of solar and storage system. 


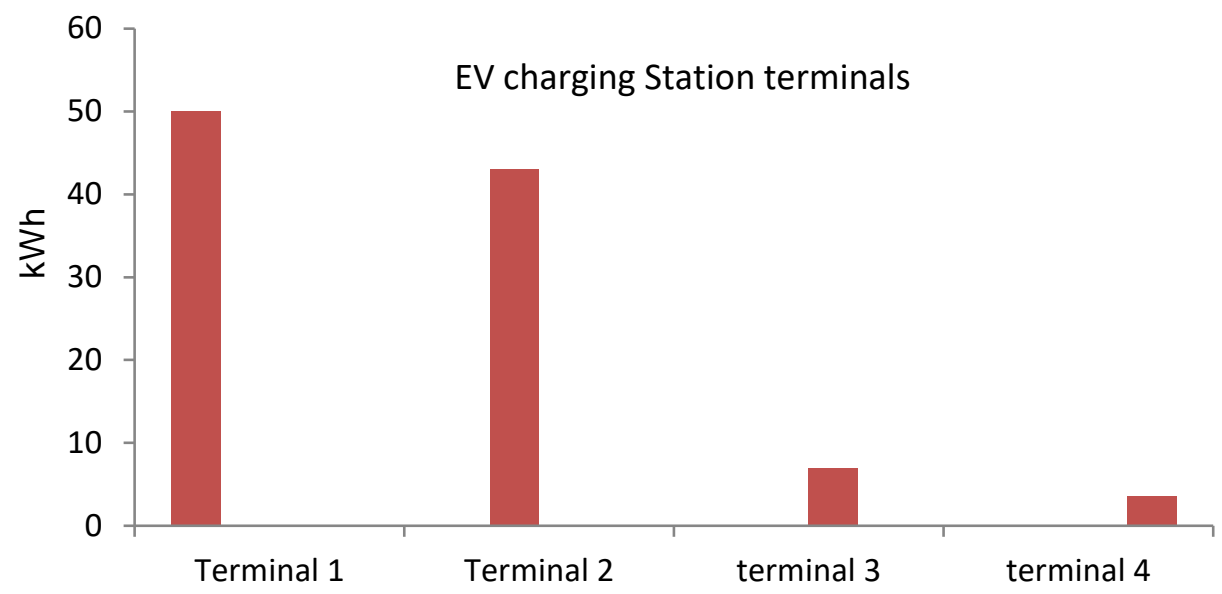

Fig. 4: Illustrates the Electric vehicles charging points at the EV station.

There are four scenarios considered to examine and analyse the energy system performance.

- When the solar system is independently supplying power to the EV charging terminal. In this case, the storage system is in off-mode. This is the best feature as energy demand is completely achieved by the renewable energy/solar system. This system also improves the environment by minimising the carbon emissions generated from the fuel generator. The energy losses are very small due to the shorter length of the electric power transmitted conductor. This scenario has the capacity to meet the energy demands at the EV station during the Peak and off-peak times.

Solar Power generation (kWh)

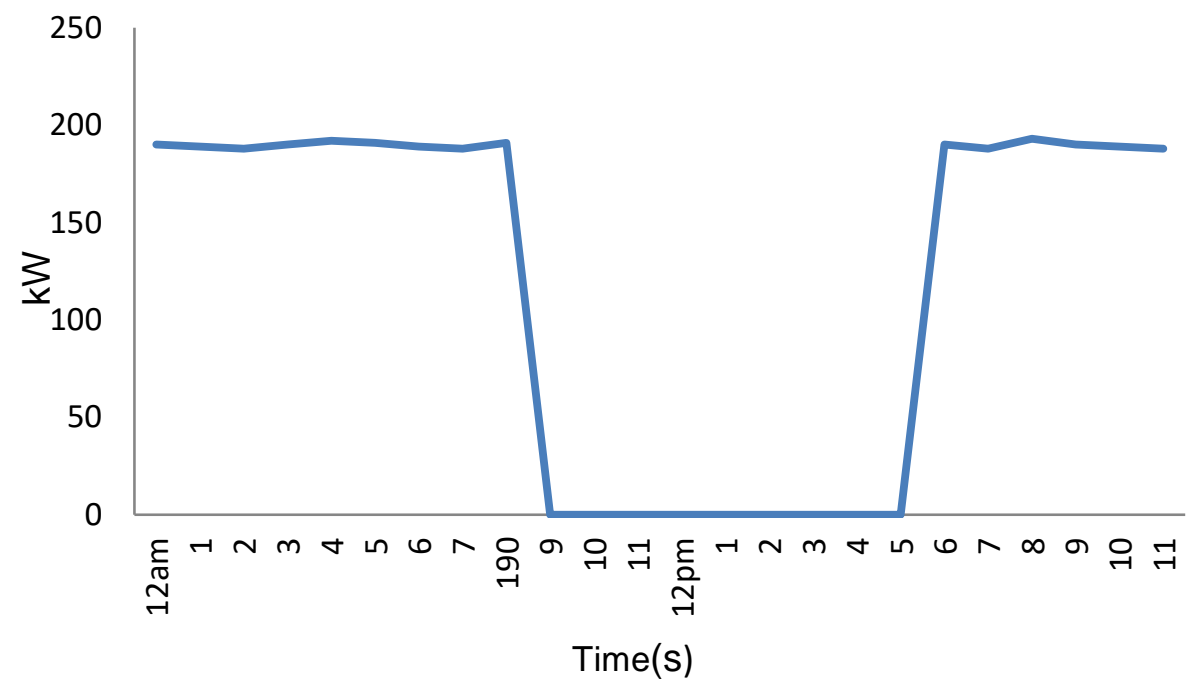

Fig. 5: The power generation by the solar system between 9pm and 5am no power is generated by the solar system. In this case the storage system and fuel generator will meet the energy demands at that time.

- The generated energy from the solar system is charging up the solar system in peak times. In this case, the EV charging terminal is consuming the energy at full capacity.

- When the storage system and fuel generator are meeting the energy demands at the EV charging station. At this point, the solar system is in off-mode and not generating any power. Fuel generator charges up the storages when energy level falls below $60 \%$. Storage system degradation is normally measured by three main features, such as the depth of discharge, temperature, and the conditions of charge. These three factors affect the performance of batteries used in the storage system. 


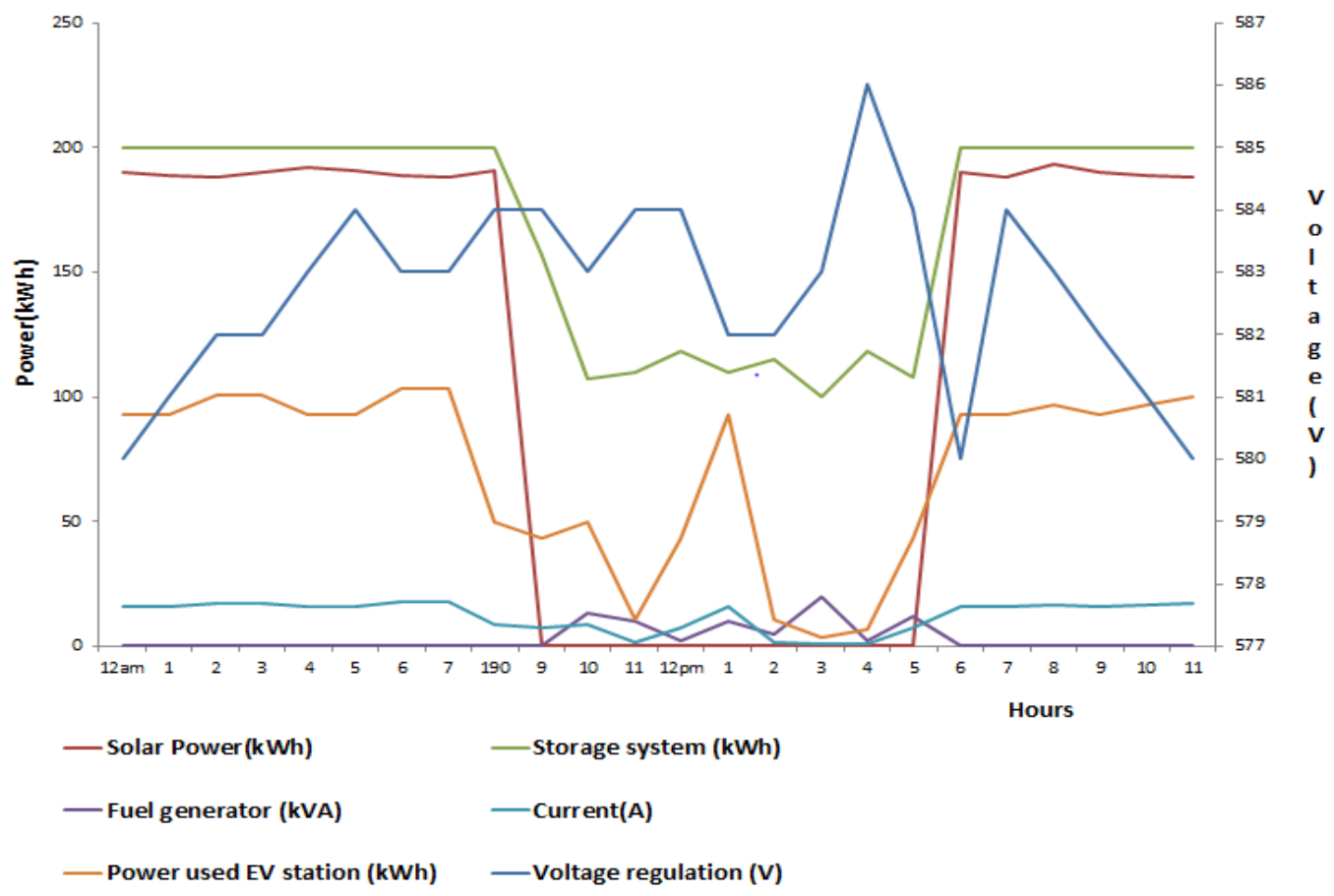

Fig. 6: The energy management at the EV charging station. In this case, the nominal power from the solar system is mitigated from $9 \mathrm{pm}$ to $5 \mathrm{am}$ where storage system is independently meeting the energy demands at the EV station. Fuel generator switched ON to charge up the storage system as the energy level falls below $60 \%$.

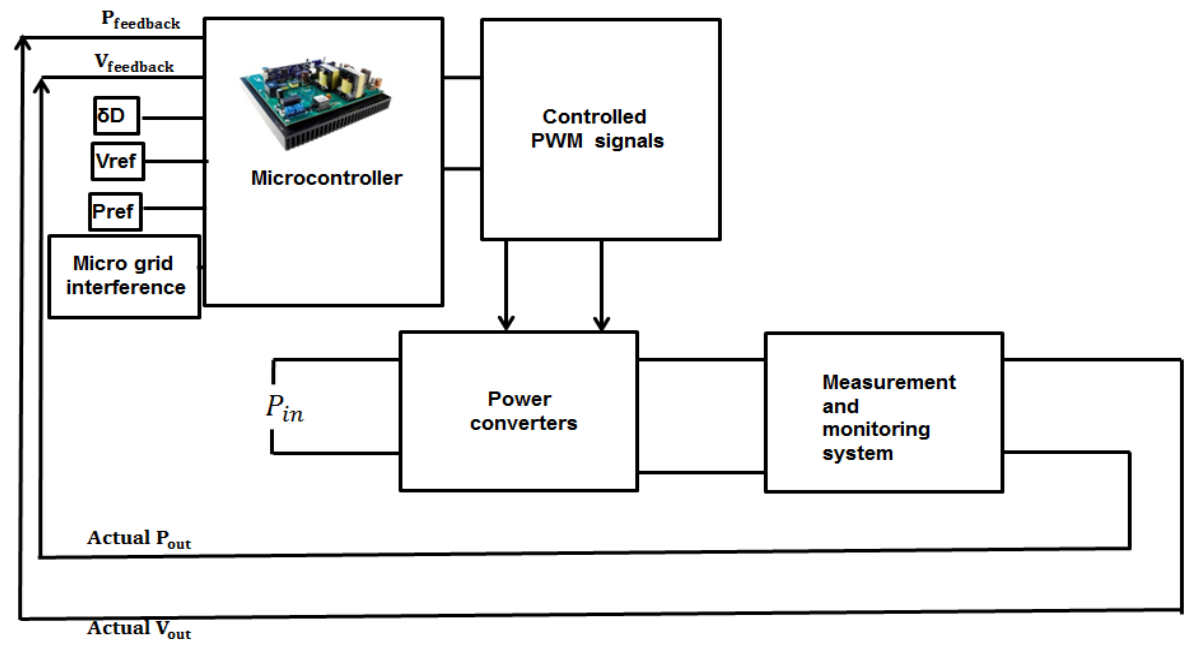

Fig. 7: The implemented control system to apply the correct duty cycle for regulating the voltage.

\section{Simulation Results}

The spikes and oscillations are detected in the voltage due to the usage of inductance and capacitance in the DC/DC power conversion and on the load side. The lower switching frequency created the higher ripples in the power supply because of the DC/DC buck converter and control system implementation in the electric vehicle charging terminal is featuring to supply the converted and regulated voltage to the electric vehicles. It is noticed that the higher inductance values reduing the losses and created lower ripples currents and to removes the transients low pass filter are used that are improving the sum of power flow relates to the numbers of vehicles being charged up at the electric-vehicles charging station. The losses in the entire system are very lower due to the shorter length of the transmitted conductor. At the start of the simulation, a 
transient in the voltage is noticed due to charging up of inductance, the capacitance in the converters and in the line. Power availability is maintained constantly at the electric-vehicle charging station irrespective of changes in temperature/irradiance at the solar charging station. The controllable bidirectional converter is maintaining the power on the EV charging terminal and charges up the storage system. To measure the power flow, measurements components are used at several points of the system. The circuit breaker is used to protect the system from the faults and short circuit current. The system is enabling the electric-vehicles to be charged up all the time from the terminal.

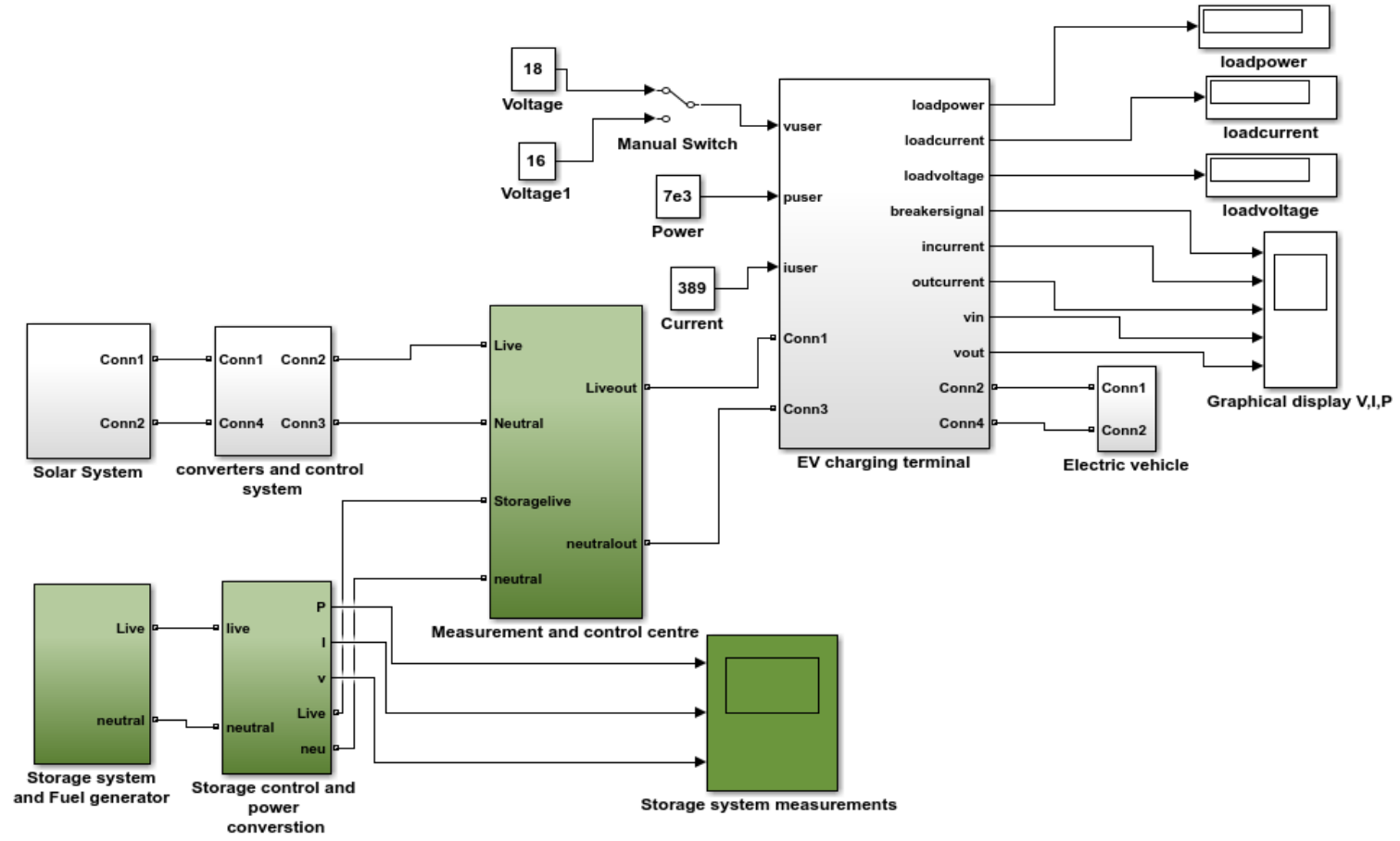

Fig. 8: The simulation model of the complete system.

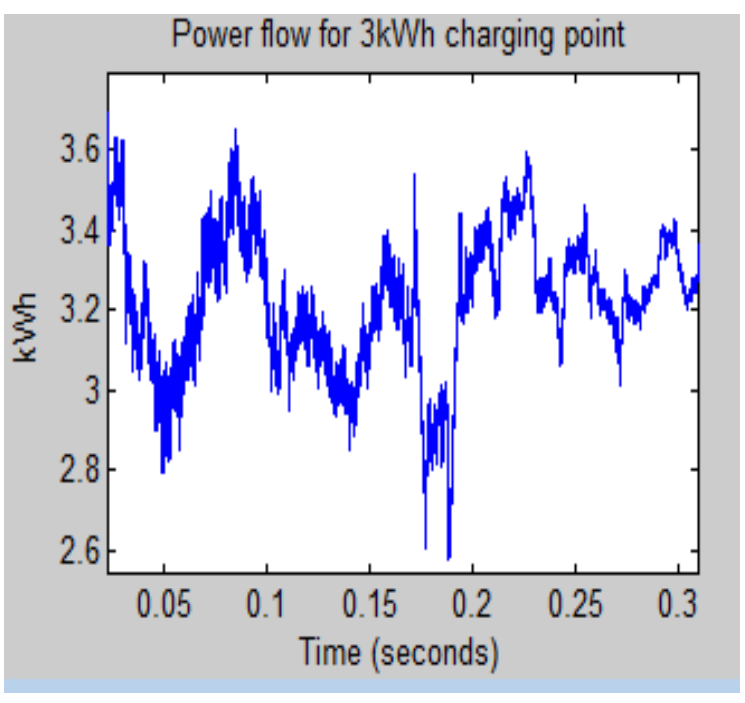

(a) Power used by $3 \mathrm{KWh}$ charging point

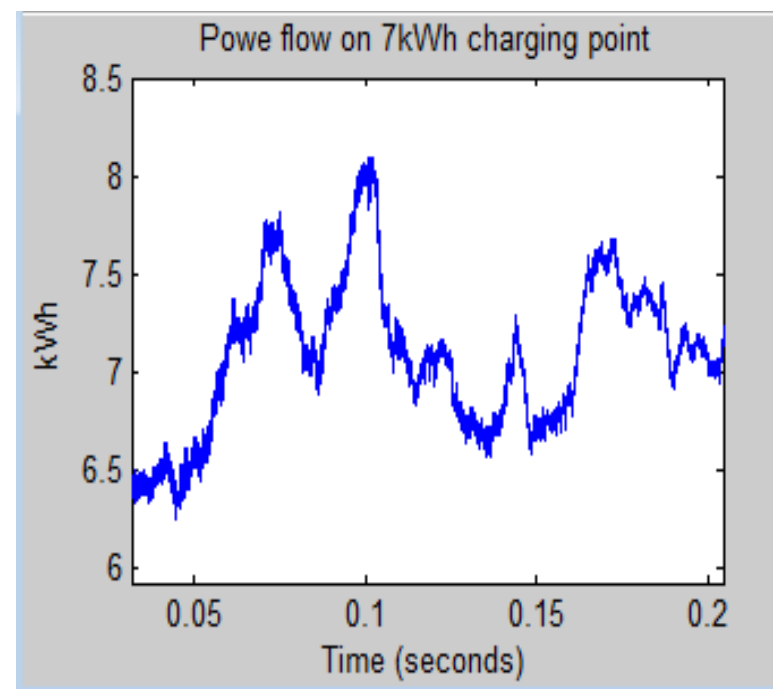

(b) Power consumption by $7 \mathrm{kWh}$ charging point 


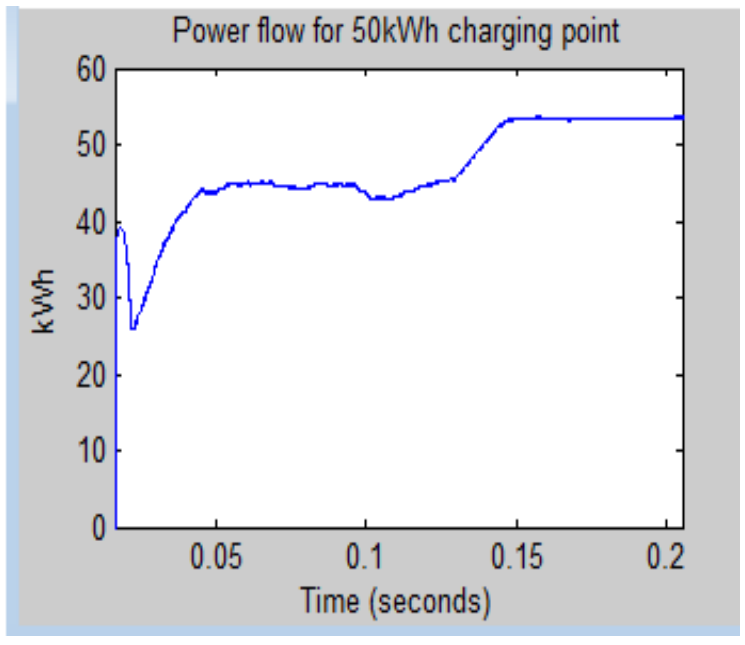

(c) Energy used by 50kWh charging point

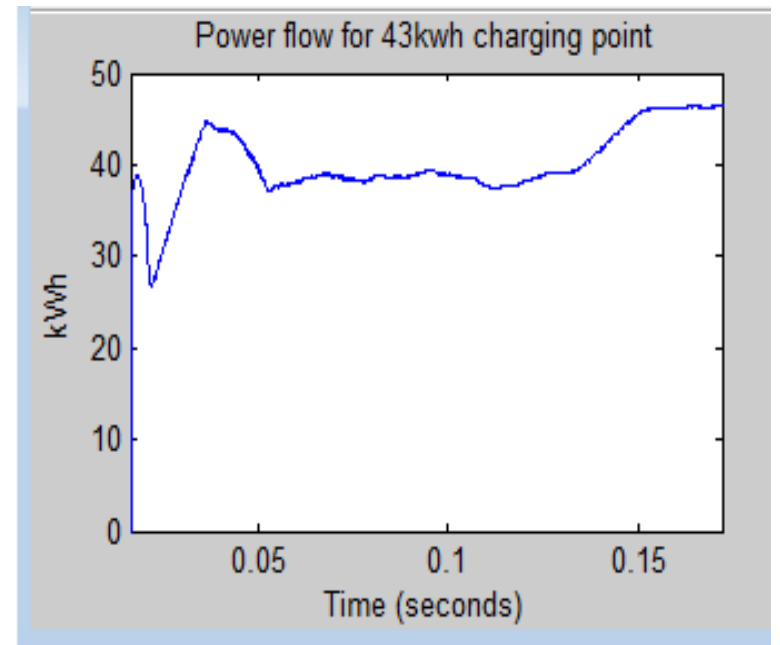

(d) Energy consumption by $43 \mathrm{kWh}$ charging point

Fig. 9: Illustrates the power consumption at the electric-vehicle charging station during the fully operational mode. ( a) Power utilised by $3 \mathrm{kWh}$ charging point from the solar power system. (b) shows the $7 \mathrm{kWh}$ charging point power consumption. (c) Energy consumption by $50 \mathrm{kWh}$ charging point. (d) Energy used by $43 \mathrm{kWh}$ charging point.

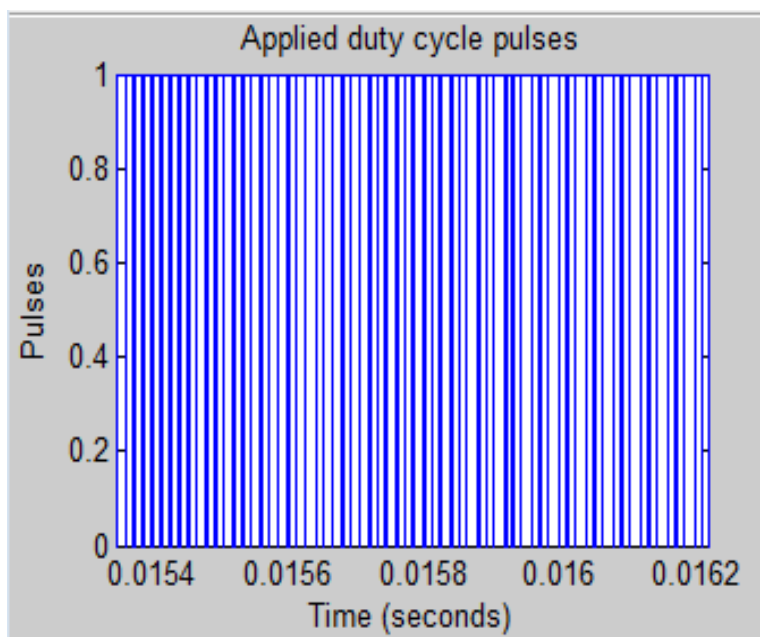

(a) Duty cycle pulses to regulate DC/DC voltage from the solar system

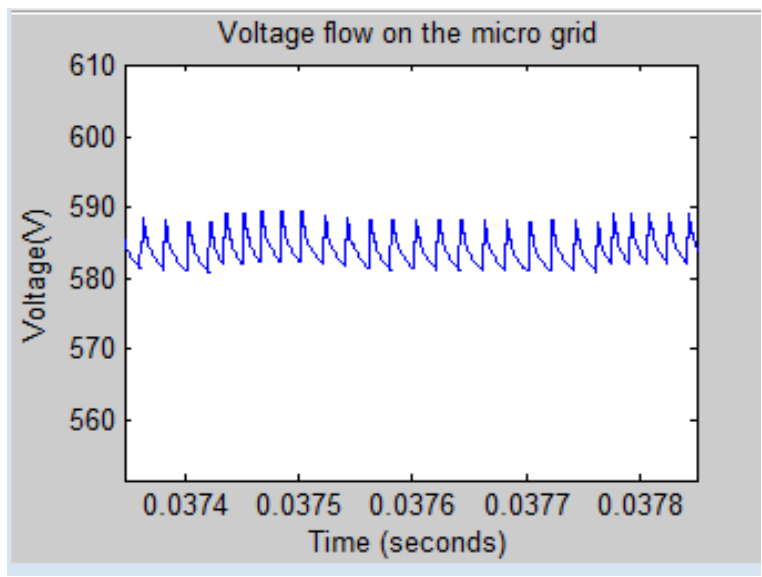

(c) Minor oscillations in voltage

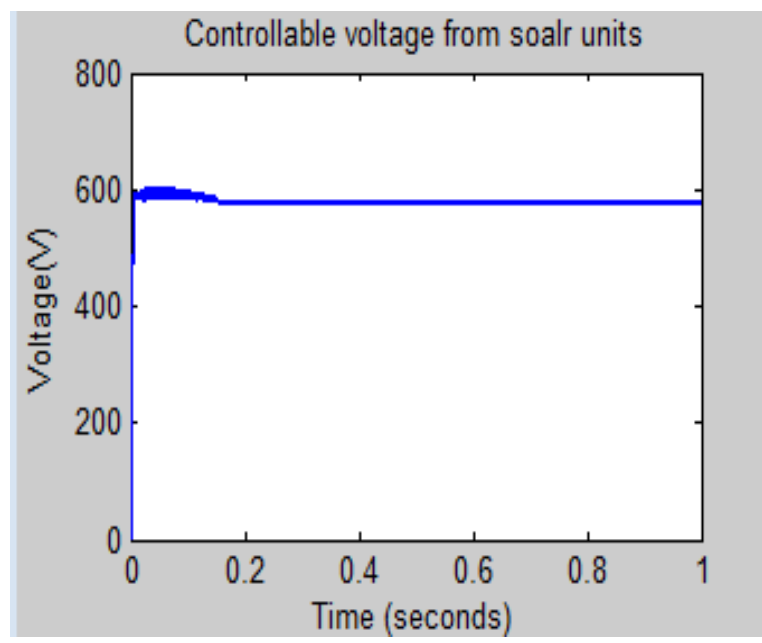

(b) Regulated voltage received from the DC/DC converter station

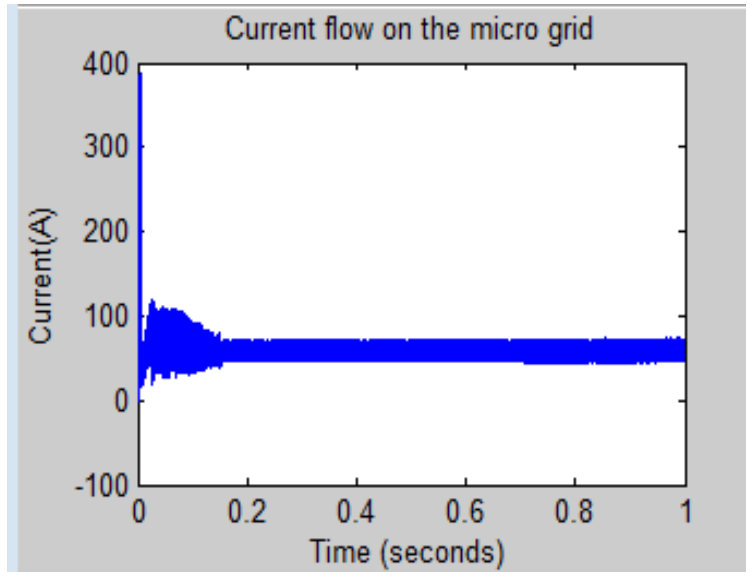

(d) Current flow in the system

Fig. 10: The voltage regulation achieved at the charging terminal from solar system/storage system. (a) Duty cycle applied to stabilise the fluctuated voltage from the solar system (b) $585 \mathrm{VDC}$ on the microgrid. This is controlled voltage from the solar system (c) The oscillations in the voltage level. (d) Current flow analysis on the simulated system. 


\section{Conclusion}

A solar energy based electric-vehicle charging station is proposed in this paper. The proposed system is capable of managing the regulated voltage to supply the required energy during the peak/off-peak times. The applied electrical control techniques improve the voltage performance irrespective of the intermittent solar energy due to the changes in irradiation/temperature. The applied electrical control system is the advancement of maximum power point tracking algorithm based incremental conductance. The advancement is the addition interference between the solar, storage and fuel based energy generation system with the micro grid control centre and the application of higher frequency to achieve the quality results. The regulation in voltage is achieved by applying the correct duty cycle to the DC/DC power converter switches where the spike/oscillations and transients are minimised by using the low pass filters. It is found that losses in the system are reduced to $1 \%$ due to shorter transmission conductor length and lesser implementation of power converters After examining the simulation results, it is concluded that DC high voltage based electricvehicle charging station reduces the charging time for the batteries of the electric vehicle. The simulation results are validated by the mathematical modelling and theoretical analysis. During the normal environmental conditions, the solar system has generated the electrical energy at full capacity that is considered to be sufficient for the EV charging station. The direction of future work is to incorporate the communication system at the electric-vehicle charging station to examine the energy flow from the solar/storage system. This communication should be linked with the smart sensors that are implemented at several points such as DC/DC solar converter, DC/DC storage converters and at the grid. This will improve the protection for the EV charging terminal during the disturbances from solar/storage or at the converters.

\section{References}

Cheng, L., Chang, Y. and Huang, R., 2015. Mitigating voltage problem in distribution system with distributed solar generation using electric vehicles. IEEE Transactions on Sustainable Energy, 6(4), pp.14751484 .

Dubarry, M., Devie, A. and McKenzie, K., 2017. Durability and reliability of electric vehicle batteries under electric utility grid operations: Bidirectional charging impact analysis. Journal of Power Sources, 358, pp.3949.

Guan, J.C. and Chen, B.C., 2017. Adaptive Power Management Strategy for a Four-Mode Hybrid Electric Vehicle. Energy Procedia, 105, pp.2403-2408.

Han, J., Kum, D. and Park, Y., 2017. Synthesis of predictive equivalent consumption minimization strategy for hybrid electric vehicles based on closed-form solution of optimal equivalence factor. IEEE Transactions on Vehicular Technology.

Liu, H. and Sun, J., 2014. Voltage stability and control of offshore wind farms with AC collection and HVDC transmission. IEEE Journal of Emerging and selected topics in Power Electronics, 2(4), pp.11811189.

Shaaban, M.F., Eajal, A.A. and El-Saadany, E.F., 2015. Coordinated charging of plug-in hybrid electric vehicles in smart hybrid AC/DC distribution systems. Renewable Energy, 82, pp.92-99.

Shen, J., Dusmez, S. and Khaligh, A., 2014. Optimization of sizing and battery cycle life in battery/ultracapacitor hybrid energy storage systems for electric vehicle applications. IEEE Transactions on industrial informatics, 10(4), pp.2112-2121.

Sheng, M., Zhai, D., Wang, X., Li, Y., Shi, Y. and Li, J., 2017. Intelligent Energy and Traffic Coordination for Green Cellular Networks With Hybrid Energy Supply. IEEE Transactions on Vehicular Technology, 66(2), pp.1631-1646. 
Tan, L., Wu, B., Rivera, S. and Yaramasu, V., 2016. Comprehensive dc power balance management in highpower three-level dc-dc converter for electric vehicle fast charging. IEEE Transactions on Power Electronics, 31(1), pp.89-100.

Yu, H. and Stuart, A.L., 2017. Impacts of compact growth and electric vehicles on future air quality and urban exposures may be mixed. Science of The Total Environment, 576, pp.148-158.

Yong, J.Y., Ramachandaramurthy, V.K., Tan, K.M. and Mithulananthan, N., 2015. Bi-directional electric vehicle fast charging station with novel reactive power compensation for voltage regulation. International Journal of Electrical Power \& Energy Systems, 64, pp.300-310.

Zhang, N., Hu, Z., Dai, D., Dang, S., Yao, M. and Zhou, Y., 2016. Unit commitment model in smart grid environment considering carbon emissions trading. IEEE Transactions on Smart Grid, 7(1), pp.420-427. 